\title{
BMJ Open A cost-benefit analysis of twice-daily consultant ward rounds and clinical input on investigation and pharmacy costs in a major teaching hospital in the UK
}

\author{
Aftab Ahmad, ${ }^{1}$ Philip J Weston, ${ }^{1}$ Mahin Ahmad, ${ }^{2}$ Dushyant Sharma, ${ }^{1}$ \\ Tejpal Purewal ${ }^{1}$
}

To cite: Ahmad A, Weston PJ, Ahmad M, et al. A cost-benefit analysis of twice-daily consultant ward rounds and clinical input on investigation and pharmacy costs in a major teaching hospital in the UK. BMJ Open 2015;5:e007367.

doi:10.1136/bmjopen-2014007367

- Prepublication history for this paper is available online. To view these files please visit the journal online (http://dx.doi.org/10.1136/ bmjopen-2014-007367).

Received 4 December 2014 Revised 6 February 2015 Accepted 10 February 2015

\section{(a) CrossMark}

${ }^{1}$ Department of Diabetes/ Endocrinology and General Medicine, Royal Liverpool University Hospital, Liverpool, Merseyside, UK

${ }^{2}$ Department of General Medicine, Royal Liverpool University Hospital, Liverpool, Merseyside, UK

Correspondence to Dr Aftab Ahmad; aftab.ahmad@rlbuht.nhs.uk

\section{ABSTRACT}

Objectives: Misuse of investigations, medications and hospital beds is costing the National Health Service (NHS) billions of pounds with little evidence that approaches centred on reducing overuse are sustainable. Our previous study demonstrated that twice-daily consultant ward rounds reduce inpatient length of stay and suggested a reduction in overuse of investigations and medications. This study aims to assess the impact of daily consultant ward rounds on the use of investigations and medications and estimate the potential cost benefit.

Settings: The study was performed on two medical wards in a major city university teaching hospital in Liverpool, UK, receiving acute admissions from medical assessment and emergency departments.

Participants and intervention: The total number of patients admitted, investigations performed and pharmacy costs incurred were collected for 2 years before and following a change in the working practice of consultants from twice-weekly to twicedaily consultant ward rounds on the two medical wards.

Outcome measures: We performed a cost-benefit analysis to assess the net amount of money saved by reducing inappropriate investigations and pharmacy drug use following the intervention.

Results: Despite a $70 \%$ increase in patient throughput $(p<0.01)$ the investigations and pharmacy, costs per patient reduced by $50 \%$ over a 12 -month period $(p<0.01)$ and were sustained for the next 12 months.

The reduction in investigations and medication use did not have any effect on the readmission or mortality rate $(p=N S)$, whereas, the length of stay was almost halved $(p<0.01)$. Daily senior clinician input resulted in a net cost saving of £336 528 per year following the intervention.

Conclusions: Daily consultant input has a significant impact on reducing the inappropriate use of investigations and pharmacy costs saving the NHS more than $£ 650 \mathrm{~K}$ on the two wards over a 2-year period.
Strengths and limitations of this study

- Although daily consultant ward rounds have been reported in the USA and Canada, our paper reports for the first time the impact of daily senior clinician input on increasing patient throughput while significantly reducing investigation and pharmacy costs. In addition, the Academy of Medical Royal Colleges has recently reported a potential savings on $£ 11.7$ million from our model of care.

- Our study demonstrates sustained cost savings over 2 years and the savings are reproducible on medical wards where twice-weekly consultant wards still persist.

- We have shown that daily consultant ward rounds can be achieved by changing the way we work without incurring extra costs while reducing inappropriate investigations and medication use, which is demonstrated by the unchanged readmission and mortality rate despite almost doubling the patient throughput.

- The study, however, only took into account the most common investigations, but given the significant reduction in investigations demonstrated, it is likely that we would have identified further cost savings if all investigations were included.

- Although our study demonstrates a reduction in investigations, the net cost savings would also be dependent on bed base and staff reduction in the respective departments. It can be argued that in the absence of bed base or staff reduction, no actual money was saved but wide spread implementation of daily consultant ward rounds in the future would allow these departments to incorporate changes in the way they work.

\section{INTRODUCTION}

The overuse of investigations in clinical medicine has been discussed over the past four decades ${ }^{1}$ and has been consistently increasing. There is little evidence that 
quality of care has proportionately improved, ${ }^{2}$ yet the burden on healthcare resources has substantially increased. ${ }^{3}$ More importantly, only $1 \%$ of haematological and less than $10 \%$ of other investigations were shown to contribute to a diagnosis suggesting investigations should be ordered responsibly. ${ }^{4}$ Furthermore, excessive and inappropriate investigations can lead to further tests and physicians treating the results rather than the patient. $^{67}$

Various reasons including lack of training and supervision of junior staff have been suggested for the inappropriate use and duplication of investigations. ${ }^{2}{ }^{3} 7-14$ The cost of investigations can range from $£ 5$ to few hundred pounds per test, with a substantial cost implication if used inappropriately in hospital settings with high patient throughput (PT). Cost containment strategies focused on clinician education, cost awareness, use of computer models, feedback and other aspects have led to wastage reduction but were either not sustainable or incurred an ongoing cost. ${ }^{15-17}$

Inappropriate use of medication is another source of resource wastage and has direct cost implications with cost savings demonstrated by implementing restriction or management policies, ${ }^{18-22}$ which again required extra resources and ongoing educational costs.

Delays in investigational procedures and inappropriate use of medication have been highlighted as factors leading to prolonged of length of stay (LoS) ${ }^{22-24}$ Senior clinician input has been shown to reduce $\operatorname{LoS}^{23}$ It is proposed that the reduced LoS and bed days is associated with significant cost savings. ${ }^{25}$

The current study aims to look at the impact of twicedaily consultant ward rounds on the number of investigations performed and the pharmacy costs compared with the traditional twice-weekly ward rounds.

\section{METHODS}

\section{Hospital setting}

The study was conducted on two general medical wards with a mixed case load of admissions from the acute admissions unit, A\&E and the clinics at the Royal Liverpool University Teaching hospital. The two wards are covered by four consultants and their teams, described elsewhere. ${ }^{23}$

\section{Cost-benefit analysis}

We performed a cost-benefit analysis of the impact of twice-daily consultant wards on the use of investigations and medication on our two busy medical wards. The main outcome measure was the per patient annual financial cost benefit of twice-daily compared with the traditional twice-weekly consultant ward rounds over a 2-year period. Since the only intervention was a change in consultant working pattern with the same number of sessions, team structure and experience, same number of staff on the wards with no extra costs incurred and no change in overheads, we were able to estimate the net change in the use of investigations and its financial costs before and after the intervention.

\section{Intervention}

Following detailed team discussions and job planning negotiations, the working pattern of the four consultants responsible for two general medical wards was completely changed from a traditional twice-weekly to twicedaily ward rounds and a week-on the ward and a week-off the ward job plan. This change provided daily consultant input in clinical decision-making as well as daily bedside teaching and supervision of junior staff and monitoring their investigation requesting and prescribing habits while keeping the staff costs neutral. The details of the changeover are described elsewhere. ${ }^{23}$

\section{Data collection}

The intervention was implemented on 1 November 2009. All data were collected by the hospital information department on a daily basis and reported on a monthly basis. To ensure sustainability of the intervention and reliability of the results, data were collected for the 2-year period following the intervention. LoS, readmission rates (RRs) and mortality rates (MRs) were obtained for the two wards. Their definitions are described elsewhere. ${ }^{23} \mathrm{RR}$ and MR data were obtained to assess any adverse effects on the quality of patient care. ${ }^{15}$ PT was the patient intake and flow through both wards over the study period and was collected to calculate the investigation and pharmacy cost per patient. The same data were also collected for the 2-year period preceding the intervention to estimate the benefit of the intervention.

The investigations studied included biochemistry (urea and electrolytes and liver function tests), full blood count, chest X-ray (CXR), CT, MRI, ventilation/ perfusion scan $(\mathrm{V} / \mathrm{Q})$, endoscopy (oesophogogastroduodenoscopy and colonoscopy). These represent the most commonly requested investigations by our wards from clinical chemistry, radiology, nuclear medicine and gastroenterology departments over the 4-year period. The total number of each investigation used between 1 November 2007 and 31 October 2011, and the cost of each investigation was provided by the respective departments. We also obtained the annual pharmacy costs for the same 4-year period from the pharmacy department. These figures were confirmed by the Royal Liverpool Hospital's finance department. Other investigations such as ECGs, C reactive proteins (CRPs), echocardiograms, etc, were not included as most of these were requested by the emergency and acute medical admission units prior to the patients' arrival on our wards.

\section{Data analysis}

The monthly mean for PT, LoS, RR, MR and investigations performed was calculated for the 2 years prior to and following the intervention. The annual mean PT 
was calculated to determine annual cost savings for the period following the intervention.

Per patient monthly mean investigations were then calculated by dividing the mean investigations by the mean PT for the 2 years prior to and following the intervention. Per patient mean monthly investigation was then multiplied with the unit cost of each investigation to obtain per patient mean monthly cost for each investigation. Per patient mean annual pharmacy cost was calculated by dividing the mean annual pharmacy cost by the mean annual PT for the two wards and reported as monthly mean for uniformity.

Cost saving benefit was then calculated by finding the difference between the mean per patient cost before and after the intervention. Finally, to calculate the total annual cost saving the mean per patient cost saving for each investigation and the pharmacy was multiplied with the mean annual PT number after the intervention. The results are reported as means \pm SD.

Since the working hours of staff and the number of clinics were unaffected, these costs remained neutral and therefore were not included. Similarly the cost for ward overheads was not included as the wards remained fully functional throughout the study period and were not affected by the intervention. The cost saving calculations and the potential savings from reduced bed days and $\operatorname{LoS}$ we reported in our previous paper $^{23}$ was beyond the scope of this study.

\section{Statistical analysis}

Statistical analysis was performed using one-way analysis of variance, and where multiple comparisons were made, Tukey and Dunnett's C test was applied depending on equal or unequal variances, respectively. The $p$ value $<0.05$ was considered significant. Results are expressed as means $\pm \mathrm{SD}$.

\section{RESULTS}

The annual means \pm SD of PT, LoS, RR and MR are shown in table 1 , which demonstrates a significant increase in PT and reduction in LoS following the intervention. Importantly, the RR and MR did not change significantly despite the increase in patient flow through the wards.

Table 1 Comparison of monthly mean of patient throughput, length of stay, readmission rate and mortality rate prior to and after the intervention

\begin{tabular}{|c|c|c|}
\hline Variable & $\begin{array}{l}\text { Monthly } \\
\text { mean } \\
(2007-2009)\end{array}$ & $\begin{array}{l}\text { Monthly mean } \\
(2009-2011)\end{array}$ \\
\hline $\begin{array}{l}\text { Patients throughput } \\
\text { (annual mean) }\end{array}$ & $\begin{array}{l}152.2 \pm 23.7 \\
(1827)\end{array}$ & $\begin{array}{l}259.7 \pm 24.0 \\
(3116)^{\star}\end{array}$ \\
\hline Length of stay (days) & $9.7 \pm 1.7$ & $5.2 \pm 0.5^{\star}$ \\
\hline Readmission rate (\%) & $18.8 \pm 2.1 \%$ & $19.3 \pm 2.4 \%{ }^{\mathrm{NS}}$ \\
\hline Mortality (\%) & $2.9 \pm 1.4 \%$ & $2.7 \pm 1.3 \% \mathrm{NS}$ \\
\hline
\end{tabular}

The monthly mean investigations, annual pharmacy costs, per patient investigation and pharmacy cost with annual cost savings are shown in table 2. Our report shows that despite the significant increase in patient flow, the daily consultant input led to a $50 \%$ reduction in the mean per patient investigations and pharmacy costs. The annual mean net cost saving benefit from reducing the investigations and pharmacy cost was $£ 336528$ per year and a total of $£ 673056$ over the 2-year study period.

\section{DISCUSSION}

This study shows that consultant ward rounds and decision-making significantly reduces the use of inappropriate investigations, pharmacy costs and LoS, resulting in a significant, sustainable year-on-year cost savings in excess of £300K. Our per patient investigation and pharmacy costs were halved and sustained over a 2-year period. More importantly, reducing the number of investigations and pharmacy use did not result in increased RRs or inpatient mortality. This study does not include the potential savings from reducing the LoS and inpatient bed days.

Overuse of investigations leading to resource wastage has been highlighted from as early as $1979 .{ }^{1}$ There is very little evidence that excessive testing improves diagnostic accuracy or patient care ${ }^{2457}$ and indeed may be harmful to patients due to misinterpretations and lead to further inappropriate testing or even potentially harmful clinical interventions. ${ }^{7}$ Several reasons for the variation and continued increase in investigations have been offered including ease of access to tests, lack of training, uncertainty of diagnosis, defensive medicine, increased patient turnover and excessive monitoring. ${ }^{27-14}$ The clinical and educational inexperience of doctors is considered one of the important factors for inappropriate tests being ordered. ${ }^{172627}$ The test ordering behaviour of doctors significantly changed by introducing guidance in the form of simple form and computer-based requests. ${ }^{14} 15$ Numerical rationing, ${ }^{2}$ notifying doctors of their test usage compared with their peers ${ }^{28}$ informing physicians of the test costs, ${ }^{29}{ }^{30}$ introducing investigation requesting protocols $^{31}$ and education of clinical staff ${ }^{32}$ have all shown to reduce inappropriate investigations. However, senior clinician input in the form of auditing the intern's charts weekly led to a $50 \%$ reduction in investigations. ${ }^{33}$ Our study has similarly demonstrated that daily consultant input can lead to a $50 \%$ reduction in unnecessary testing without compromising patient safety.

Although the various strategies used to reduce overuse of investigations demonstrated cost benefits, their implementation has cost implications and are difficult to sustain. ${ }^{15-17}$ Developing paper-based or computer-based request forms or computer-based models in itself require funding but, furthermore, need ongoing educational programmes to cope with the rapid turnover of junior doctors to ensure proper use of these models on a 
Table 2 Comparison of mean monthly investigations, pharmacy and per patient cost with calculated annual cost savings prior to and after the intervention

\begin{tabular}{|c|c|c|c|c|c|c|}
\hline $\begin{array}{l}\text { Investigations (cost per } \\
\text { unit) }\end{array}$ & $\begin{array}{l}\text { Monthly mean } \\
\text { (2007-2009) }\end{array}$ & $\begin{array}{l}\text { Monthly mean } \\
(2009-2011)\end{array}$ & $\begin{array}{l}\text { Per patient } \\
\text { monthly mean } \\
\text { 2007-2009 } \\
\text { (cost) }\end{array}$ & $\begin{array}{l}\text { Per patient } \\
\text { monthly mean } \\
\text { 2009-2011 } \\
\text { (cost) }\end{array}$ & $\begin{array}{l}\text { Mean cost } \\
\text { saving per } \\
\text { patient }\end{array}$ & $\begin{array}{l}\text { Mean annual } \\
\text { cost saving } \\
\text { for } \\
\text { the period } \\
2009-2011\end{array}$ \\
\hline Biochemistry (£5) & $1007.2 \pm 112.4$ & $834.5 \pm 134.4$ & $6.6 \pm 1.2(£ 33)$ & $3.2 \pm 0.9(£ 16)^{*}$ & $£ 17$ & $£ 52972$ \\
\hline $\mathrm{FBC}(£ 5)$ & $423.9 \pm 27.9$ & $326.7 \pm 28.3$ & $2.8 \pm 0.5(£ 14)$ & $1.2 \pm 0.2(£ 6)^{*}$ & $£ 8$ & $£ 24928$ \\
\hline CT (£228) & $17.3 \pm 6.1$ & $16.7 \pm 6.0$ & $0.12 \pm 0.04(£ 27)$ & $0.06 \pm 0.02(£ 14)^{\star}$ & $£ 13$ & $£ 40508$ \\
\hline MRI (£460) & $3.6 \pm 2.6$ & $3.1 \pm 1.7$ & $0.02 \pm 0.01(£ 9)$ & $0.01 \pm 0.007(£ 5)^{*}$ & $£ 4$ & $£ 12464$ \\
\hline CXR (£30) & $36.0 \pm 8.4$ & $32.3 \pm 8.0$ & $0.24 \pm 0.07(£ 7)$ & $0.12 \pm 0.03(£ 4)^{\star}$ & $£ 3$ & $£ 9348$ \\
\hline V/Q scan (£271) & $7.3 \pm 3.0$ & $6.8 \pm 2.6$ & $0.05 \pm 0.07(£ 14)$ & $0.03 \pm 0.01(£ 8)^{\star}$ & $£ 6$ & $£ 18696$ \\
\hline Endoscopy (£492) & $20.5 \pm 5.8$ & $16.7 \pm 5.5$ & $0.13 \pm 0.03(£ 64)$ & $0.06 \pm 0.02(£ 29)^{*}$ & $£ 35$ & $£ 109060$ \\
\hline Pharmacy (annual cost) & (£84 919) & $(£ 75518)$ & $£ 46$ & $£ 24$ & $£ 22$ & $£ 68552$ \\
\hline Total cost & - & - & - & - & $£ 108$ & $£ 336528$ \\
\hline
\end{tabular}

consistent basis. ${ }^{13}$ Similarly, developing and running ongoing educational programmes to promote optimal use of investigations requires senior clinician time in addition to other cost implications, while there are some questions on the value of such programmes. ${ }^{17} 34$ Introducing investigation requesting protocols can be useful in reducing investigations but arguably can lead to unnecessary testing in patients who clinically may not need them. ${ }^{75}$ In our previous study, ${ }^{23}$ we compared the impact of daily consultant ward rounds on LoS between our and two other wards with similar case load and demonstrated halving of the LoS on our wards, whereas, the LoS essentially remained unchanged on those two wards practising the traditional twice-weekly consultant ward rounds. While most hospitals ${ }^{36}$ including ours have been reporting a year on year increase in the use of investigations, our model of consultant working pattern allowing daily senior clinician input into clinical decision-making led to a reduction in investigations without any extra costs and obviated the need for developing special requesting models or ongoing educational programmes requiring extra clinician teaching time. We were able to provide relevant and focused bedside teaching and supervision to the junior doctors on appropriate use of investigations and help them understand results interpretation. Our model has led to considerable cost savings while preventing patient discomfort or compromising quality of care.

It is debateable whether the reduced LoS we observed following twice-daily ward rounds was due to a reduction in unnecessary tests which caused delayed discharges, or if reducing LoS by better senior clinician's decisionmaking led to a decrease in unnecessary testing because of the considerably shorter stay of patients in the hospital. Evidence suggests that prolonged LoS leads to increased thromboembolic and hospital-acquired infection risk, which inevitably results in more investigations and treatment costs. ${ }^{37} 38$ Reducing the LoS has been shown to decrease infection risk, ${ }^{39}$ comorbidities and mortality $^{37}$ and has an impact on clinical outcomes. ${ }^{40}$ Appropriate use of antibiotics helps reduce the LoS. ${ }^{41}$ These measures impact on pharmacy costs, which is another major resource wastage in hospital medical care. Doctors lack of understanding and knowledge plays a role in inappropriate use of antibiotics and education programmes, and restriction policies have shown to improve appropriate use of antibiotics. ${ }^{21} 4243$ Similar to strategies employed in reducing investigations, the educational programmes required to implement these policies are labour intensive and time consuming with cost implications. ${ }^{21}$ The halving of LoS we achieved by daily consultant ward rounds may have contributed significantly in reducing the pharmacy costs by a combination of reducing hospital-acquired infections and appropriate use of antibiotics by providing daily supervision and guidance to junior doctors.

We anticipate that the savings reported in this study are an underestimation of the total potential savings since all the resources groups used on the wards, such as cardiology resources (eg, ECG, echocardiogram), microbiology or other blood tests (eg, thyroid function tests, CRP), were not included as they were either already ordered and performed in the admission units or by the specialist teams reviewing these patients on our request. In addition, societal costs, patient satisfaction, quality of life and the potentially reduced hospital-acquired morbidities because of the reduced LoS were beyond the scope of the study but may have highlighted further significant cost savings. The financial implications of reducing the number of bed days per patient have to be considered. It can be argued that in the absence of bed base or staff reduction, no actual money was saved. However, the recent report from the Academy of Medical Royal Colleges, based on our previous study, ${ }^{23}$ has suggested a potential saving of $£ 11.7$ million and a reduction of 1900 tonnes of carbon per year by reducing the LoS and bed days using our model. ${ }^{23}$ Although our model was implemented on only two medical wards, 
the case mix is similar to most medical wards in most hospitals.

Although various strategies used to reduce investigations and pharmacy costs demonstrated cost savings, ${ }^{14} 15$ 27-31 they either had cost implications of developing and providing ongoing education to staff, lacked sustainability because of the rapid junior doctor turn over or were even detrimental to clinical decisionmaking. ${ }^{15-17}$ Almost all approaches are centred on reducing investigations whereas our study method is based on a change in consultant working pattern allowing senior clinical input and decision-making on a daily basis improving clinical diagnosis, which in turn has led to reduced investigations and reducing LoS. This is a more holistic approach allowing daily education of staff, supervising the use of tests and medications while improving clinical decision-making that has led to a $50 \%$ reduction in LoS, investigations and pharmacy laboratory costs saving in excess of $£ 300 \mathrm{~K}$ per year. This is not only sustainable and reproducible but has very little cost implications if properly implemented.

Acknowledgements The authors would like to acknowledge our information and finance department for the help they provided in gathering and confirming the data and the unit costs of investigations. They are indebted to Dr Peter Williams, the Medical Director, for his support in bringing about these changes. They appreciate the help provided by the clinical chemistry, radiology, gastroenterology, nuclear medicine, pharmacy and all other departments during this change. They are grateful to Colette Turner, their directorate manager for helping them implement this model of change. Special thanks to Professor Munir Ahmad who helped them with the statistical analysis of the data.

Contributors AA, PJW, DS and TP conceived and designed the study. MA collated and analysed the data. AA analysed and interpreted the data. All authors drafted and revised the article and approved the final version.

Funding This research received no specific grant from any funding agency in the public, commercial or not-for-profit sectors.

Competing interests None.

Provenance and peer review Not commissioned; externally peer reviewed.

Data sharing statement No additional data are available.

Open Access This is an Open Access article distributed in accordance with the Creative Commons Attribution Non Commercial (CC BY-NC 4.0) license, which permits others to distribute, remix, adapt, build upon this work noncommercially, and license their derivative works on different terms, provided the original work is properly cited and the use is non-commercial. See: http:// creativecommons.org/licenses/by-nc/4.0/

\section{REFERENCES}

1. Abrams ME. Costs of tests. J R Coll Physicians Lond 1979;13:217-18.

2. Dixon $\mathrm{RH}$, Laszlo J. Utilization of clinical chemistry services by medical house staff: an analysis. Arch Intern Med 1974;134:1064-7.

3. Kwok J, Jones B. Unnecessary repeat requesting of tests: an audit in a government hospital immunology laboratory. J Clin Pathol 2005;58:457-62.

4. Hampton J, Harrison M, Mitchell J, et al. Relative contributions of history-taking, physical examination, and laboratory investigation to diagnosis and management of medical outpatients. BMJ 1975;2:486

5. Sandler G. Costs of unnecessary tests. BMJ 1979;2:21.

6. Angell M. Cost containment and the physician. JAMA 1985;254:1203-7.

7. Fraser C, Woodford F. Strategies to modify the test-requesting patterns of clinicians. Ann Clin Biochem 1987;24:223-31.
8. Ashley T, Pasker P, Beresford J. How much clinical investigation? Lancet 1972;299:890-3.

9. Davidoff F, Goodspeed R, Clive J. Changing test ordering behavior: a randomized controlled trial comparing probabilistic reasoning with cost-containment education. Med Care 1989:45-58.

10. DeKay ML, Asch DA. Is the defensive use of diagnostic tests good for patients, or bad? Med Decis Making 1998;18:19-28.

11. Grego P, Eisenberg JM. Changing physicians' practices. $N$ Engl J Med 1993;329:1271-4

12. Thompson RS, Kirz HL, Gold RA. Changes in physician behavior and cost savings associated with organizational recommendations on the use of routine chest $X$ rays and multichannel blood tests. Prev Med 1983;12:385-96.

13. Wong ET, McCarron MM, Shaw ST. Ordering of laboratory tests in a teaching hospital: can it be improved? JAMA 1983;249:3076-80.

14. Young D. An aid to reducing unnecessary investigations. BMJ 1980;281:1610.

15. Attali M, Barel $\mathrm{Y}$, Somin M, et al. A cost-effective method for reducing the volume of laboratory tests in a university-associated teaching hospital. Mt Sinai J Med 2006;73:787-94.

16. Eisenberg JM. An educational program to modify laboratory use by house staff. Acad Med 1977;52:578-81.

17. Grossman RM. A review of physician cost-containment strategies for laboratory testing. Med Care 1983:783-802.

18. Barenfanger J, Short MA, Groesch AA. Improved antimicrobial interventions have benefits. J Clin Microbiol 2001;39:2823-8.

19. Girou E, Stephan F, Novara A, et al. Risk factors and outcome of nosocomial infections: results of a matched case-control study of ICU patients. Am J Respir Crit Care Med 1998;157:1151-8.

20. Gross R, Morgan AS, Kinky DE, et al. Impact of a hospital-based antimicrobial management program on clinical and economic outcomes. Clin Infect Dis 2001;33:289-95.

21. Ozkurt Z, Erol S, Kadanali A, et al. Changes in antibiotic use, cost and consumption after an antibiotic restriction policy applied by infectious disease specialists. Jpn J Infect Dis 2005;58: 338.

22. Shorr AF, Micek ST, Welch EC, et al. Inappropriate antibiotic therapy in Gram-negative sepsis increases hospital length of stay. Crit Care Med 2011;39:46-51.

23. Ahmad A, Purewal TS, Sharma D, et al. The impact of twice-daily consultant ward rounds on the length of stay in two general medical wards. Clin Med 2011;11:524-8.

24. Marchette L, Holloman F. Length of stay: significant variables J Nurs Adm 1986;16:12-20.

25. Academy of Medical Royal Colleges. Protecting resources, promoting value: a doctor's guide to cutting waste in clinical care. 2014. http://www.aomrc.org.uk/

26. Detsky AS, McLaughlin JR, Abrams HB, et al. Do interns and residents order more tests than attending staff? Results of a house staff strike. Med Care 1986:526-34.

27. Griner PF. Use of laboratory tests in a teaching hospital: long-term trends reductions in use and relative cost. Ann Intern Med 1979;90:243-8.

28. Schroeder SA, Kenders K, Cooper JK, et al. Use of laboratory tests and pharmaceuticals: variation among physicians and effect of cost audit on subsequent use. JAMA 1973;225:969-73.

29. Cohen DI, Jones $\mathrm{P}$, Littenberg $\mathrm{B}$, et al. Does cost information availability reduce physician test usage? A randomized clinical trial with unexpected findings. Med Care 1982:286-92.

30. Henderson D, D'Alessandri R, Westfall B, et al. Hospital cost containment: a little knowledge helps. Clin Res 1979;27:279.

31. Blery C, Szatan M, Fourgeaux B, et al. Evaluation of a protoco for selective ordering of preoperative tests. Lancet 1986;327: 139-41.

32. Griner PF, Liptzin B. Use of the laboratory in a teaching hospital: the implications for patient care, education, and hospital costs. Ann Intern Med 1971;75:157-63.

33. Martin AR, Wolf MA, Thibodeau LA, et al. A trial of two strategies to modify the test-ordering behavior of medical residents. $N$ Engl J Med 1980;303:1330-6.

34. Greenland P, Mushlin Al, Griner PF. Discrepancies between knowledge and use of diagnostic studies in asymptomatic patients. Acad Med 1979;54:863-9.

35. Connelly D, Steele B. Laboratory utilization. Problems and solutions. Arch Pathol Lab Med 1980;104:59-62.

36. Vegting IL, van Beneden M, Kramer MH, et al. How to save costs by reducing unnecessary testing: lean thinking in clinical practice. Eur $J$ Intern Med 2012;23:70-5.

37. Clarke A. Why are we trying to reduce length of stay? Evaluation of the costs and benefits of reducing time in hospital must start from the objectives that govern change. Qual Health Care 1996;5:172. 
38. Graves N, Weinhold D, Tong E, et al. Effect of healthcare-acquired infection on length of hospital stay and cost. Infect Control Hosp Epidemiol 2007;28:280-92.

39. Nathwani D. Impact of methicillin-resistant Staphylococcus aureus infections on key health economic outcomes: does reducing the length of hospital stay matter? J Antimicrob Chemother 2003;51 (Suppl 2):ii37-44.

40. Hayes JH, Cleary R, Gillespie W, et al. Are clinical and patient assessed outcomes affected by reducing length of hospital stay for total hip arthroplasty? J Arthroplasty 2000;15:448-52.
41. Battleman DS, Callahan M, Thaler HT. Rapid antibiotic delivery and appropriate antibiotic selection reduce length of hospital stay of patients with community-acquired pneumonia: link between quality of care and resource utilization. Arch Intern Med 2002;162:682-8.

42. Jones SR, Barks J, Bratton T, et al. The effect of an educational program upon hospital antibiotic use. Am J Med Sci 1977;273:79-86.

43. Avorn J, Soumerai SB. Improving drug-therapy decisions through educational outreach. A randomized controlled trial of academically based detailing. N Engl J Med 1983;308:1457-63. 